\title{
A LEARNING ACTIVITY DESIGNED FOR A LARGE GROUP OF STUDENTS IN A MECHANICAL ENGINEERING SUBJECT USING PEER-ASSESSMENT TO ENCOURAGE DEEPER LEARNING
}

\author{
J.L. Suñer, J. Carballeira \\ Departamento de Ingeniería Mecánica y de Materiales, Universitat Politècnica de València \\ (UPV) (SPAIN)
}

\begin{abstract}
This paper presents a learning activity for the subject "Machines and Mechanisms" in a bachelor's degree in Electrical Engineering that allows to work on several specific and generic competences for a large group of students. This activity consists of seeking a real mechanism and following some steps to analyze it, so that the students can improve their knowledge and understanding of the subject area. This activity is planned in a way that forces the students to put different skills into play, further than just dealing with the technical issues of it. Peer-assessment is carried out alongside the activity to encourage deeper learning. A full description of the activity is presented, together with the assessment tools and the results for this course.
\end{abstract}

Keywords: assessment, generic competences, Master's Thesis.

\section{INTRODUCTION}

The design of learning activities that are able to develop and to assess both the technical-scientific competences (specific) and the generic ones makes them not only useful to grade the students but also very interesting to promote their learning experience. After some experiences conducted in the recent years using different teaching-learning methodologies and evaluation strategies [1], the authors have come with a new proposal for this year. This proposal has been used in a subject of Mechanism and Machine Theory in the $2^{\text {nd }}$ year of a bachelor's degree in Electrical Engineering within the Technical University of Valencia (UPV).

There were about 80 students enrolled in this course and only one teacher responsible for the subject. So, from the experiences before, one of the first issues to consider was to come with an activity that would make grading not very time-consuming. Second, the activity should be challenging enough to make it motivating for the students, but not too difficult so that they could do most of the work autonomously. Finally, it should be planned carefully with various checkpoints along the semester so that the feedback could be provided on time.

To design the activity different methodologies were considered, especially to work on generic competences. The use of active methodologies is particularly interesting in this case [2]. Also, an Assessment for Learning approach has proved to be very effective [ 3 and so it was a requirement for the activity.

The use of peer-assessment has been very successful in some teaching interventions before [4], so it was introduced in the design of the activity. There are many references that claim the advantages of this methodology [5,6]. Two of them were of special interest in this case:

- It implies the use of generic competences by the students and promotes their lifelong selflearning skills.

- It promotes deep understanding and learning.

But there are also some drawbacks that are worth mentioning:

- The validity and the consistency of the co-evaluation, so that there are not high deviations from the expert's evaluation.

- The lack of experience and skills of the students to provide an accurate grading to their peers can be discouraging for them.

These drawbacks can be minimized by following some recommendations: 
- To make the criteria as clear as possible by writing the different learning outcomes as simple questions [7].

- To make it anonymously and to check the consistency using the expert's evaluations [8].

\section{METHODOLOGY}

With all these requirements in mind, a learning activity was designed to fulfil as many of them as possible. This activity involves a comprehensive analysis of a real mechanism from the point of view of the Theory of Machines and Mechanisms. This analysis goes from a historical review to the dynamic analysis using numerical simulations and analytical methods and includes the modelling of the mechanism by using any suitable technique such as 3D printing, CAD-CAE, recycled parts and so on. Some examples of these models are shown in figure 1.
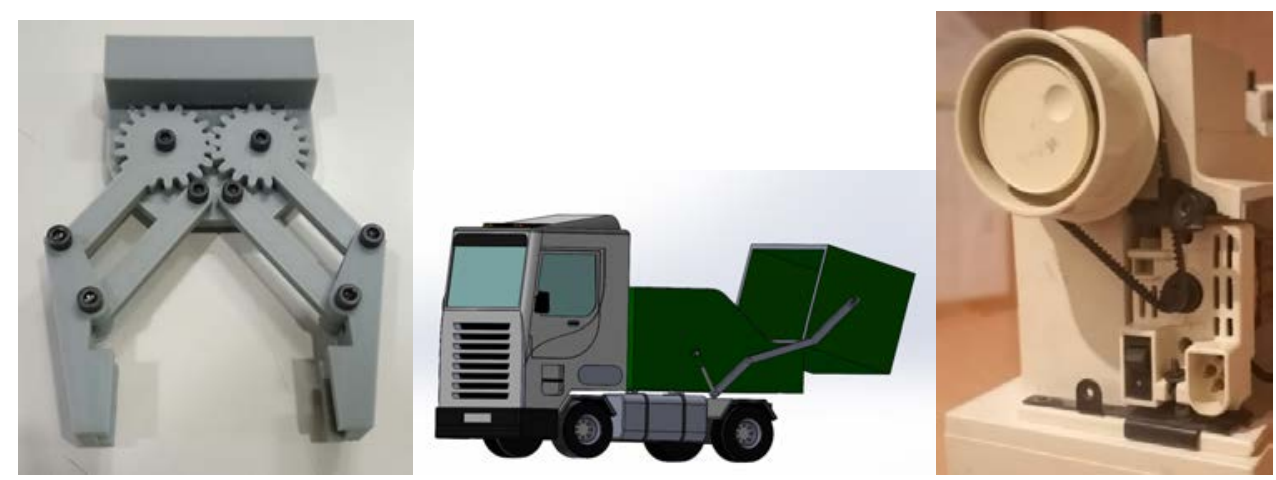

Figure 1. Different models created by using 3D printing, computer aided design software and recycled components.

The activity consists of a set of deliverables during the semester and is done in teams of four students. The main objectives of every deliverable are related to the contents of the lectures that are being taught at that time, but the students have to put some additional skills into play in order to successfully prepare a good report and a final oral presentation. This approach provides with some opportunities to work on and to assess their generic competences.

Using Tuning project convention [9], some of the competences developed in this activity are:

- The ability to search for, process and analyse information from a variety of sources.

- The ability to apply knowledge in practical situations.

- The ability to identify, pose and resolve problems.

- The ability to work in a team.

- The ability to plan and manage time.

- The determination and perseverance in the tasks given and responsibilities taken.

- The skills in the use of information and communications technologies.

- The ability to communicate both orally and through the written word in first language.

Some checkpoints are scheduled:

1 After the first lectures and with some advice from the teacher, the teams seek a real mechanism with the characteristics required.

2 By the $4^{\text {th }}$ week of the semester, the teams should release the first deliverable with the historical review and a research on alternative mechanisms to the one they have chosen but with the same capabilities.

3 By the $8^{\text {th }}$ week of the semester, the kinematic analysis should be delivered.

4 By the $12^{\text {th }}$ week of the semester, an inverse dynamic problem related the mechanism should be solved. 
5 By the end of the semester, a direct dynamics problem should be solved, and a final report comprising all the ones before, together with a final oral presentation, are required.

During the semester, the teams are supposed to attend at least twice to some office hours to inform the teacher on the progress of their work. Also, there are some guidelines given by the instructor for every step so that the students know what they are expected to do.

As a way of assessing the activity, a set of peer-assessment questionnaires were devised. The students were asked to volunteer for this assessment after explaining them the advantages of taking part in it. Some of the students decided not to participate and this provided with a great opportunity to compare with the students who did.

These questionnaires were implemented in a website accessible by the students to make it easier for grading. The students answered these questionnaires after reviewing one report from another team and considering the guidelines previously given to minimize the bias of the correctors. In the first deliverable, the grades and comments of the students were compared with the ones given by the teacher. For the next deliverables, an analysis of the deviations between the grades given by the students and the ones given by the teacher was done. The students were provided with the feedback necessary to improve their final report.

There were three main goals to analyse these deviations:

- To check if the students with the less deviations were also the ones with the best performance in the subject, as a positive correlation would be expected from the authors' point of view.

- To follow up the students and to check if collaborating in the peer-assessment would help them to improve their performance in the subject.

- To review the topics with the greater deviations because it could mean that these topics were not addressed properly during the classes.

For the peer-assessment of the final report, two questions were set up to evaluate the self-perception of the students and to promote their critical thinking:

- Do you think that you could improve your work after studying this report?

- Do you think this report deserves more, less or the same grade as yours?

\section{RESULTS}

In this section, the main results for the last year are shown. There are different quantities that can be compared. On one side, there are the results from the peer-assessment. On the other side, there are the grades of two exams, and the final grade of the subject.

The results from the peer-assessment work this way. There were 3 deliverables and 1 final report. To evaluate each of them, 4 questions were asked regarding the main issues at every stage of the activity. There were four answers to every question: A, B, C or D, so that answer A was a description of an outstanding solution, to answer $D$ that described a poor solution to the issue.

For instance, for the first deliverable, one important issue was that the mechanism had only 1 degree of freedom (dof) and that it was a planar mechanism.

- A - It is a 1 dof mechanism, or it can be easily decomposed into a set of planar mechanisms with 1 dof.

- $\mathrm{B}$ - It is a mechanism, but it is not planar, or it is not 1 dof, or it can not be easily decomposed into a set of planar mechanisms with 1 dof.

- $\mathrm{C}-\mathrm{It}$ is a mechanism, but it is unclear what function it has in the machine, and so it is not easy to determine its degrees of freedom.

- $\mathrm{D}-\mathrm{It}$ is not a mechanism.

If all the questions were answered with an $A$, then the team would be given the maximum grade. The deviation between the corrector and the teacher was determined as a difference between the answers of both. I.e., if the corrector would consider that the answer was B and the teacher would consider that it should be $A$, then a deviation of 1 would be marked. Accordingly, the maximum deviation for a question could be 3 ( $A$ to $D$, or $D$ to $A$ ), and the total maximum deviation for one deliverable could be 
12 (3 times 4 questions). To make this analysis more understandable, a normalized deviation is used from 0 (no deviation at all) to 1 (deviation in all the questions).

In figure 2, the final grades of the students that took part in the peer-assessment ( $\mathrm{Y}$-axis) are shown together with their deviations as correctors (X-axis). This grading goes from 0 to 10 , where 5 is needed to pass the subject. As it can be observed, there is not any correlation between these two quantities. There are students with a good performance in the subject who have a large deviation as correctors, as well as students with a poorer performance but a smaller deviation.

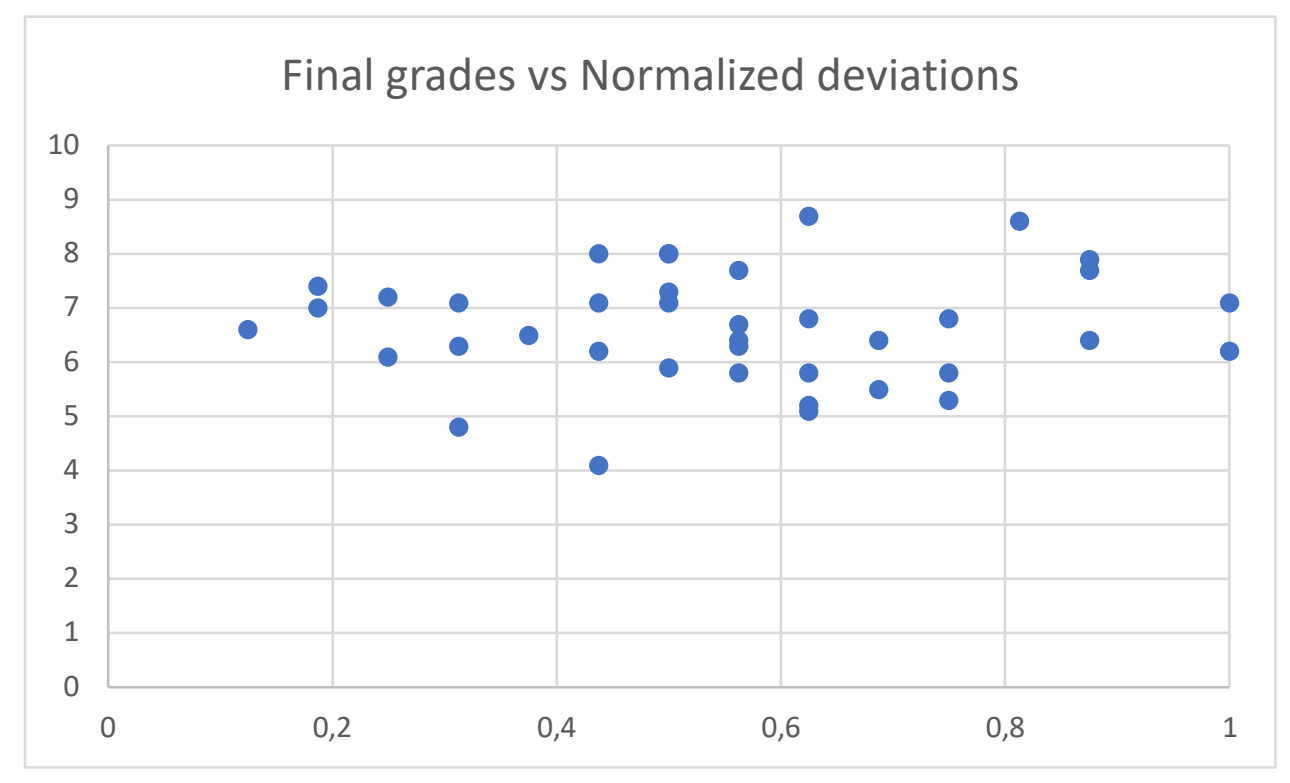

Figure 2. Final grades vs deviations.

In table 1, the differences in the exams and the final grades of those who participated in the peerassessment and those who didn't are shown. As it can be observed, there is a small gap in the exams, but a more relevant difference in the final grade, that includes the activity grade. Clearly, those who participated also did better deliverables and final report.

Table 1. Averages in the exams and the final grade.

\begin{tabular}{l|c|c|c}
\hline \hline & Exam 1 & Exam 2 & Final \\
\hline Peer-assessment group & 4.4 & 6.6 & 6.7 \\
\hline Not participated & 4.1 & 6.3 & 5.5 \\
\hline \hline
\end{tabular}

\section{CONCLUSIONS}

The main conclusions that can be drawn so far from this experience are:

- The students that participated in the peer-assessment got a better performance in the subject. They were more motivated, and they appreciated the feedback provided as correctors.

- The analysis of the deviations in the peer-assessment is very interesting. First, it shows if the students are understanding the questions, or if any of them should be re-written; second, it allows to better distribute the reports among the students, as a function of their performance in the learning. And finally, it helps to grade the development of some generic competences.

- A sort of fatigue was noticed in the students that took part in the peer-assessment, with greater deviations at the final stages. It could be due to the increase in the academic demand when the end of the semester is closer. But also, these were the more difficult issues in the subject, so it may be a sign of the discouragement pointed out in the Introduction as a drawback of this methodology. Some training seems to be necessary to obtain a good grading from the peerassessment method. 


\section{ACKNOWLEDGEMENTS}

The authors acknowledge the financial contribution by the Universitat Politècnica de València through the project PIME/2018/DPTO.IMM.

\section{REFERENCES}

[1] J. Carballeira, J. Martínez-Casas, O. Sahuquillo, A. Sonseca, J.L. Suñer, P. Vila, F.D. Denia, J.J. Ródenas and O. Marco, "Chapter 5 - Assessment of problem-solving skills and capactiy for applying knowledge in practice in subjects related to mechanical and materials engineering," in Advances in Higher Education (J. Domenech, J. Lloret, M.C. Vincent-Vela, E. de la Poza and E. Zuriaga, eds.), pp. 71 - 88, ISBN 978-84-9048-496-8, Valencia: Editorial UPV, 2016.

[2] A. Villa and M. Poblete, Competence-based learning: A proposal for the assessment of generic competences. Bilbao: University of Deusto, 2008.

[3] B.S. Bloom, G.F. Madaus and J.T. Hastings, Evaluation to Improve Learning. New York: McGrawHill, 1981.

[4] J. Carballeira, A. Rovira, J.L. Suñer, P. Vila, F.D. Denia, J.J. Ródenas, M. Tur, "The use of peerassessment to improve the evaluation of generic competences in subjects related to mechanical engineering," in INTED2017 Proceedings, pp. 7115-7123, Valencia: IATED, 2017.

[5] D. Nulty, "A Guide to Peer and Self Assessment: Approaches and Practice Strategies for Academics," Griffith Institute for Higher Education. Griffith University, 2008.

[6] M. Langan and P. Wheater, "Can students assess students effectively? Some insights into peerassessment," Learning and Teaching in ACTION, vol. 2, no. 1, 2003.

[7] L.A. Lim Yuen Lie, "Implementing effective peer assessment," CTDL Brief, vol. 6, no. 3, 2003.

[8] S. Bostock, "Student peer assessment," Learning Technology, 2000.

[9] Tuning project, "Generic competences," Accessed 27 June, 2019. Retrieved from https://www.unideusto.org/tuningeu/competences/generic.html 